\title{
Compensation of the Driver as a Motor Accident Victim in Cameroon: A Critical Appraisal of the Cima Code*
}

\author{
Abue Ako Scott Eke \\ Catholic University Institute of Buea, Buea, Cameroon \\ Email: scottypyppenn@yahoo.ca
}

Received 13 April 2015; accepted 22 August 2015; published 25 August 2015

Copyright (C) 2015 by author and Scientific Research Publishing Inc.

This work is licensed under the Creative Commons Attribution International License (CC BY). http://creativecommons.org/licenses/by/4.0/

(c) (i) Open Access

\begin{abstract}
In Cameroon, the law that governs the compensation of motor accident victims is the CIMA Code. This law fully recognizes the driver as being a victim that is liable to compensation in case he suffers from a motor accident. Equally at the same time, the law has put in place special modalities which the driver must fulfill in order to receive complete or partial compensation. This is particularly important because the same law provides for a different regime of compensation when it comes to the case of victims non-driver. A driver could therefore be described as a victim sui generis. This paper does a critical appraisal of the procedural and substantive aspects inherent in the law of compensation, relevant to the driver-victim.
\end{abstract}

\section{Keywords}

Tort, Compensation, Motor Accident, CIMA Code, Victims, Motor Vehicle Insurance, No Fault System, Fault System, Civil Liability

\footnotetext{
*Conférence Interafricaine des Marches d'Assurance. The CIMA Code was adopted in 1993 to harmonise aspects of insurance in some French speaking countries of west and central Africa. These countries have signed and ratified the CIMA treaty and have agreed to be bound by the insurance legislation (CIMA Code) that forms an annex to the treaty. The Federal Islamic Republic of Comoros has also signed the agreement but has not yet ratified it. The Code itself came into existence in February 1995 and consists of six books covering life as well as non-life business. The treaty and the Code grew out of a desire to rationalise and develop local insurance markets as well as to protect insurance policy holders and victims of accidents. The CIMA organisation which replaces CICA collaborates closely with insurance authorities in individual member countries. Its main objectives are to build up the insurance industries safe guarding the interest of policy holders, protecting technical reserve of insurers, advising national governments on insurance matters and supervising the insurance markets. The treaty also created a supranational supervisory body known as CRCA which is widely credited for bringing discipline to insurance markets that it supervises.
} 


\section{Introduction}

Understanding the basis on which the driver is qualified as an indemnifiable victim under the CIMACode $e^{1}$ is quite difficult though fascinating. Difficult because of the twists and bends that exist in the law on compensation when it comes to indemnifying the driver-victim and fascinating because it's new to the law on compensation. The driver-victim receives a completely different treatment from that received by other category of victims under the CIMA Code. The Code has included drivers in the category of indemnifiable victims ${ }^{2}$ and thanks to this inclusion, drivers who are victims of motor accidents can now benefit compensation from insurers. But this favour treatment given to drivers does not come without a price tag. In fact there are lots of strings attached. It is a completely complicated process as the Code has so many loopholes and ambiguities which are left for the courts to interpret in order to discern the intentions of the legislator. The driver-victim does not receive the same treatment which other categories of victims ${ }^{3}$ receive and this has been clearly enunciated in article $227^{4}$ of the Code. According to this section, damages suffered by the driver-victim do not automatically engage the responsibility of the insurer. This is because the law that governs the compensation of victims of motor accident though being the no-fault system ${ }^{5}$ reverts back to the principle of fault system ${ }^{6}$ when it comes to compensating the driver victim. The fault system is therefore applied to determine the fault of the driver which contributed to the occurrence of the accident. This has the effect of partially or completely exonerating the insurer from any liabilities towards the driver-victim in terms of compensation. The driver victim under the CIMA code is that victim who benefits from compensation only when his personal responsibility in causing the accident has been disengaged. It is the purpose of this paper to carry out a critical analyses of the conditions under which a driver victim will be compensated and the aspects that would constitute his compensation. In this light, this paper will bring out the weaknesses inherent in the law of compensation and make proposals where necessary.

\section{Conditions for the Compensation of the Driver-Victim under the CIMA Code}

Article $231^{7}$ of the CIMA code has instituted a system of compensation at the benefit of motor accident victims. The insurer is obliged to make a compensation offer within a given period of time ${ }^{8}$. Under article 226 of the Code $^{9}$, the driver is listed in the category of indemnifiable victims under the law on compensation.

But however this does not come without a string attached to it as article $227^{10}$ of the CIMA Code states:

"The fault committed by the driver of a motor vehicle shall have the effect of reducing or excluding the compensation for bodily injuries and material damages sustained by him. This reduction or exclusion shall be enforceable against the driver's beneficiaries and persons indirectly affected. When the collision of two or several vehicles do not permit the establishment of liability incurred, each of the driver shall receive from the other drivers only half of the compensation for the bodily injury or material damage he suffered. When the driver of a motor vehicle is not the owner of the said vehicle, the fault committed by this driver may be invoked against the owner for compensation for damages caused to his vehicle. The owner shall have the right of action against the driver subject to the provisions laid down under article 42".

It could therefore be understood from the above article that unlike other categories of victims whose faults are not taken into consideration, the driver's fault plays an active role in determining whether he is entitled to comder to determine whether he could compensated or not after suffering from a motor accident. Where he was found to have played a major role in causing the accident and depending on the gravity of such a fault, the insurer would either partially or completely be exonerated from paying compensation to the victim. Therefore his causal role in the accident played an important part in determining whether the victim is entitled to compensation or not.

${ }^{7}$ This article states "irrespective of the claim the victim may make, the insurer who covers third party liability of an accident involving a motor vehicle must present within a maximum of twelve months from the date of the occurrence of the accident, a compensation offer to the victim who suffered the injury”.

${ }^{8}$ The maximum duration for such offers as stated under article 231 of the Code is twelve months.

${ }^{9}$ This article states that "the driver or custodian of a vehicle mentioned in article 225 may not invoke an Act of God or act of third party against the victims including the driver".

${ }^{10}$ Captioned "effects of driver faults and impossibility to evaluate the faults committed", as amended by Ministerial Council Decision of 24 April 1999.
} 
pensation or not after the occurrence of a motor accident in which he is a victim. This role may exonerate the insurer from his responsibility to compensate the driver either partially or completely. This therefore brings us to the notion of proving fault on the part of the driver. It can therefore be stated without any fear of contradiction that the driver is the only category of victim whose compensation relies on the fault system. Therefore it is only when the driver's responsibility has been disengaged with respect to the accident, that he may be compensated. Acts like negligence, contributory negligence, careless driving and driving under the influence of drug ${ }^{11}$ and alcohol if proven on the part of the driver will have the effect of completely or partially exonerating the insurer from his liabilities towards the driver-victim. The Cameroonian Penal Code has expressly criminalized driving under the influence of drugs ${ }^{12}$ and drivers driving without the appropriate license for the category of vehicle for which they drive. According to this section,

"The punishment by section 289 (1) shall be doubled for an offence committed by the driver of any vehicle;

a) Who is drunk or drugged when driving; or

b) Who has not the license required for driving the vehicle in question..."

Before the enactment of the 1989 Ordinance $^{13}$, Cameroonian law subscribed to the principle of fault in the determination of the civil liability ${ }^{14}$ of the person responsible for causing the road traffic accident. Therefore, a person injured as a result of a motor accident will recover compensation only if it was determined that the defendant was at fault ${ }^{15}$. The action in negligence under English speaking Cameroonian law is akin to an action under article 1382 and 1383 of the Civil Code applied in French speaking Cameroon. These provisions of the Civil Code were devoted to obligations which arose out of the fact that, one person has caused harm to another, either because of the direct fault of that person or the indirect fault of a person in that the harm was actually caused by another person or thing for which he or she was deemed to be responsible. However, for responsibility to be established there is the necessity for a causal link to be established. Article $225^{16}$ of the CIMA Code provides for the necessity of the causal role of the vehicle for civil liabilities to be established. Once a road accident has been caused by a motor vehicle, the responsibility of the person who drove the vehicle will be considered. The causal link between the accident and the damage is thus a condition for the existence of liability under the CIMA Code. The relationship between the accident and the action of the vehicle must be established for the implementation of the right to compensation. Article 225 therefore retains causality as a condition for the law of responsibility in road accidents. Once there is material intervention of the vehicle in the realization of the damage, the causal link is presumed. Therefore, the following conditions must be proven in order for the driver to be a victim worthy of compensation.

\subsection{Occurrence of an Accident Caused by a Motor Vehicle ${ }^{17}$}

The Ordinance of $13^{\text {th }}$ December $1989^{18}$ defines road traffic accident as every accident which includes a motor vehicle. This definition is really a shallow one. There is a need therefore to look at the definition of motor accident as used in insurance law, which defines it as "a sudden unforeseen event involving a motor vehicle with negative consequences which is independent of the will of the insured". The CIMA Code does not explicitly define motor accident but Article 225 (1) of the CIMA Code ${ }^{19}$ provides the rights to compensation only to the vic-

\footnotetext{
${ }^{11}$ Drugs considered under this category include Cannabis, Cocaine, Antemafine type-drugs, ketamine, opioids, benzodiazepine and other miscellaneous drugs. See Wolf K., et al. “driving under the influence of drugs”. Report from the Expert Panel on Drug Driving. March 2003.

${ }^{12}$ In its Section 90(1) (a).

${ }^{13}$ This was the first piece of national legislation on motor accident first enacted in Cameroon. It was in this law that the no-fault system of compensation was first introduced. It had a lot of similarities with the French Badinter Law of 1985.

${ }^{14}$ A Civil Law requirement to compensate another because of an unlawful injury to his/or her person or property. It is known in civil law jurisdictions as la "responsabilite civile" and to some English authors as delictual liability. It is to the Civil Law what tort law is to the Common Law.

${ }^{15}$ Before 1989, the Common Law of England, the Fatal Accident Acts 1846-1864 were applicable in English Cameroon mindful of section 11of the Southern Cameroons High Court Law of 1955.

${ }^{16}$ This article states that "the provisions of this code shall apply; even when they are transferred in pursuance to a contract, to the victims of an accident caused by a motor vehicle, as well as it trailers or semi-trailers".

${ }^{17}$ According to Decree No. 79/341 of 3 September 1979, a motor vehicle shall mean "any power driven vehicle including trolley-buses which is normally used for carrying persons or goods or for drawing such vehicles. It does not cover tractors, public work vehicles or industrial vehicles which are only incidentally used for transport”.

${ }^{18}$ Article 2(1).

${ }^{19}$ This article states that "the provision of this Code shall apply, even when they are transferred in pursuance of a contract, to the victims of an accident caused by a motor vehicle, as well as its trailers or semi-trailers". This section introduces the chapter on the compensation of victims.
} 
tims of an accident caused by a motor vehicle, its trailers and semi-trailers. Therefore the CIMA Code only applies when the accident was caused by a motor vehicle. So in reality, the driver could only be indemnified only when the damage caused to him was as a result of an accident with another motor vehicle. Tramways and other forms of mechanically propelled vehicles have therefore been excluded under the CIMA Code. According to the learned Pr. M.S. Tumnde ${ }^{20}$, this is where the CIMA code obtains its originality [1] and this writer supports this view. This is because the CIMA Code actually differentiates itself from the Badinter law ${ }^{21}$ in France and the 1989 law $^{22}$ in Cameroon. Whereas in these two texts it is enough that the vehicle should be involved in an accident, the CIMA Code requires that the accident should be caused by a motor vehicle or its trailers or its semi-trailers. Therefore as per the CIMA Code, the damage must be caused by a motor vehicle, that is, the motor vehicle must have played a role in causing the damage. In my opinion this was done in a bid to reduce endless difficulties in determining causality and to facilitate the attribution of responsibility.

\subsection{The Victim Must Be Identified as the Driver}

For the purpose of compensating the driver-victim ${ }^{23}$, the person who suffered damage as a result of the accident must be identified as the driver. Article $226^{24}$ of the CIMA Code speaks of the driver, but how ever falls short of giving us a proper definition of who a driver is. The question that arises here is who constitutes a driver for the purpose of the accident? Identifying the driver has always been a difficult task. Questions do arise like when does a person fall under the ambit of the category of a driver? At what particular moment of the accident is the consideration taken? The response here seems to be a simple one: for the purpose of the accident, the driver is one whom at the time of occurrence of the accident was not only steering the vehicle, but the vehicle was in motion. This is actually to say that the driver must not only be on the steering, but the vehicle must be in motion and he must be controlling the vehicle at the time of the occurrence of the accident. The requirement for the vehicle to be in motion is an important one when associated with the requirement of controlling the vehicle; it is only in motion [2]-[5] that the driver could effectively be conducting the vehicle. Therefore for the purpose of compensating the driver-victim, a driver injured in a stationed vehicle is not considered to be a driver. Thus we understand that for the purpose of compensation, the person driving the car can be considered as the driver at one time and at other times under different circumstance, he is deemed not to amount to a driver. Here, we are told that the vehicle must be in motion but we are not told on which category of roads the car should be used. Therefore by extension, one can rightly say that anywhere where a car is in motion amounts to a road even within a private residence ${ }^{25}$ and therefore the person in control of the vehicle at the time is deemed to be the driver. However, what happens when a driver is knocked down after he parks his vehicle and steps out, what does the law says about such a victim, since it is clear that he no longer falls within the scope of a driver as analyzed above. It has been held by the courts that every driver who has left his vehicle either voluntarily or involuntarily automatically becomes pedestrian ${ }^{26}$. Therefore a driver is knocked down by a motor vehicle automatically becomes a pedestrian and is compensated as such. This is because when out of his car, he is automatically considered as a pedestrian. It is very vital to understand the notion of the driver at the time of the accident because of the different regime of compensation that is apportioned to them, differing completely from that apportioned to other category of victims.

\footnotetext{
${ }^{20}$ Professor of Laws and Dean of the Faculty of Social and Management Sciences, University of Buea, Cameroon.

${ }^{21}$ Law No.085-677-1985 $5^{\text {th }}$ July. This is the French law on compensation of motor accident victims. This law aims to improve the situation of the road accident victims and accelerate their injury payment process. This law made significant modifications like imposing a time table for insurers within which to put forward settlement offers. It also created various classes of privileged victims who (subject to very limited exceptions) became entitled as, of right, to compensation irrespective of traditional liability rules. This includes pedestrians, cyclists and passengers. The position of drivers of motorized under this regime have become less clear cut under this regime of compensation.

${ }^{22}$ Alternatively referred to as the 1989 Ordinance.

${ }^{23}$ Recognized as a victim under article 226 of the CIMA Code.

${ }^{24}$ This article states, "The driver or custodian of a vehicle mentioned in article 225 may not invoke an act of God or an act of third party against the victim including the driver".

${ }^{25}$ In Bugge v Taylor (1947) 1 K.B. 198, a hotel forecourt habitually used by the public as a road has been held to be a road, whereas in Thomas v. Dando (1951)2 K.B.520, a car park was held not to be a road.

${ }^{26}$ Ref. Cass., Civ., 11 décembre 1991, Affaire Dame PETIOT C/Cie Le secours et autres: Juris—Data no. 003288, cassation de CA de Lyon, 6e Chamber Civ., 8 mars 1990.
} 


\subsection{Absence of Fault on the Part of the Driver}

Article 227 of the CIMA Code ${ }^{27}$ clearly states that the fault committed by the driver shall have the effect of partially or completely exonerating the insurer from his liability towards the driver-victim. It is therefore mandatory that the driver plays no role in causing the accident for him to benefit from full compensation. This places the driver in a completely abstract position when compared with other category of compensable victims like pedestrians $^{28}$. This is because the latter's fault or contribution is not taken in to consideration when determining liability for compensation. Thus where there is a damage as a result of a motor accident, the must be compensation to the latter. As mentioned above, the fault system ${ }^{29}$ is used in the determination of liability when it concerns drivers who are victims of motor accidents. This provision of the CIMA Code is however identical to the Badinter Law of 1985 in France. Like its French counterpart, the CIMA Code speaks of the driver's fault but gives no exact definition of constitutes the driver's fault and which acts that subsequently lead to a motor accident would amount to the driver's fault. The CIMA Code is equally silent on the circumstances in which a driver's fault may completely or partially exonerate the insurer from his duty to compensate the driver. It is therefore left for the courts to appreciate the circumstance in each case and these circumstances will differ from case to case. Therefore we discover that the doctrine of contributory negligence ${ }^{30}$ plays an important role in determining the role played by the driver and the amount of compensation due the driver-victim. The gravity of the driver's fault will therefore have a direct impact on the amount of compensation. In many cases, authors have converged on the fact that the driver's fault is one of an exceptional gravity that leads to the occurrence of the accident. The general tendency is that the courts will interpret the driver's fault very widely ranging from offences arising from the qualification of the driver to offences committed by the driver on the road.

\subsubsection{Attribution of Faults Based on Qualification and Documentation}

This may occur where the victim is not legally qualified to be a driver at the time of the occurrence of the accident. Before a person is qualified to be a driver, he must be the holder of a valid driving license which has been issued after due training ${ }^{31,32}$, and must be covered by a compulsory third party liability insurance ${ }^{33}$. It should be noted that decree no.79/341 of September 3, 1979 does not define a driving license; neither does it elaborate on what will constitute an invalid driving license. But from simple common sense one would understand that it is a document evidencing the fact that the driver has successfully undergone due driving training for the category of vehicle which he intends to drive and has therefore obtained the necessary authorization to drive a particular category of motorized land vehicle ${ }^{34}$. On the other hand, still following the trend of common sense reasoning, an invalid driving license would mean one which was not issued by the competent authority or even though issued by the latter, has not been renewed after the time limit for its usage has expired. Thus where a driver is a victim of an accident, and it is discovered that the driver does not possess a driving license or he possesses an invalid license, this will be sufficient to attribute fault on the driver. Where there is no third party liability insurance cover, fault would also be imputed.

\subsubsection{Faults Committed While Driving}

This refers to faults committed by the driver which is not in conformity with driving regulations laid down in the

\footnotetext{
${ }^{27}$ As amended by Ministerial Council Decision of $24^{\text {th }}$ April 1999.

${ }^{28} \mathrm{As}$ defined by Wikipedia, a pedestrian is a person travelling on foot whether walking or running. In some communities, those travelling using tiny wheels such as roller skates, skateboards and scooters as well as wheel chair users are also included as pedestrians. In contemporary times, the term usually refers to someone walking on a road, sidewalk or pavement but this was usually not the case historically.

${ }^{29}$ Supra at Pg. 1.

${ }^{30}$ Contributory negligence in Common Law jurisdictions is generally a defense to a claim based on negligence, an action in tort. The principle is relevant to the determination of liability and is applicable when claimants or plaintiffs have through their own negligence contributed to the harm they suffered. For example a pedestrian crosses a road negligently and is hit by a driver who was driving negligently. Since the pedestrian has equally contributed to the accident, he may be barred from complete and full recovery of damages from the driver or their insurers because the accident was less likely to happen if it weren't their failure to keep a proper lookout.

${ }^{31}$ According to chapter IV (section I) of the decree no. 79/341 of $3^{\text {rd }}$ September 1979, instituting the Highway Code, "no person shall drive any hidden vehicle without possessing a valid driving license for the category of vehicle being driven".

${ }^{32}$ Chapter IV (section I) (2) of the same degree goes further to state that "driving licenses shall be issued only to candidates who have successfully passed a driving test in the category for which it is to be valid".

${ }^{33}$ Compulsory motor insurance is governed by Book II of the CIMA Code.

${ }^{34}$ Chapter I of decree no. 79/341 of $3^{\text {rd }}$ September 1979 defines a motorized land vehicle as "any power driven vehicle, including trolley-buses, which is normally used for the carrying of persons or goods by road or for drawing of such vehicles. It does not cover tractors, public works vehicles or industrial vehicles”.
} 
Highway Code. The first category of fault here is;

1) Negligent driving ${ }^{35}$.

One of the fundamental duties incessantly expected of the driver is to exercise due care while driving. The requirement to exercise due care on their part is extremely high as when compared to that expected of their peers in other non-driving professions. This highest requirement for care could easily be understood because when it comes to driving, it is human lives that are at stake. Negligence may be obvious violation of traffic law for example like running a red light. Common examples of driver negligence include driving without head lamps on at night, failing to look before turning, failing to wear corrective lenses where the driver has poor eyesight or not using a blinker during a turn. It should be noted that driver negligence could be established where the driver does not exercise reasonable care to protect people and property. Negligent driving however differs from reckless driving where drivers demonstrate willful disregard for safety. In negligent driving, the driver is aware of danger to persons and property but simply neglects every precaution.

2) Disrespect of driving speed and laws

The speed at which a driver is required to drive by virtue of the Highway Code depends on the category of vehicle driven by the driver. The provisions of the law are very important as infringement of these speed limits can be calculated to constitute a fault on the part of the driver. According to decree No.79/341 "Every driver shall in all circumstances have his vehicle under control and drive it with care. He shall adjust his speed with due regard to the condition of his vehicle, its load, density of traffic, atmospheric conditions..."36

According to this provision and relating to speed, drivers are expected to always exercise care and diligence both in their driving conduct and their rate of acceleration. Therefore, failure by the driver to observe these standards as prescribed by law will be sufficient to be used against him as constituting fault for the purpose of compensation. This duty of reasonable care and due diligence is especially required but not limited to when a driver is crossing a built up area. This is because even in a non-built up area where his visibility is inadequate, he is equally required to exercise the same.

However, one may wonder how built up an area may be for the driver to exercise his duty. The law does not specifically state whether it should be of a sparse nature or dense nature. Therefore, it is the opinion of this researcher that the driver has the obligation to exercise due diligence and care even if the area is so sparsely constructed that there may be just two or three buildings. The rationale for this duty is that, wherever an area is built-up, the is automatically human presence in that area and it becomes incumbent to exercise care so as to protect lives of these of these people which is the very purpose for the putting in place of the driving laws. In this trend of reasoning, article $8(2)^{37}$ states that the maximum speed allowed in built-up areas is $60 \mathrm{~km} / \mathrm{hr}$. for light cars and $32 \mathrm{~km} / \mathrm{hr}$. for heavy vehicles.

Fault may equally be imputed on the driver where he fails to maintain the minimum distance which is supposed to be between him and the vehicle ahead of him both in built-up and non-built up areas and where such errors subsequently lead to the occurrence of a motor accident. In general the required distance is 10metres for vehicles weighing more than $3500 \mathrm{~kg}$ outside a built-up area.

Any driver wishing to make a notable change in the speed or direction of his vehicle shall first make sure he can do so without risk and warn other road users of his intentions. Therefore, drivers have the obligation by law to always notify road users in case they wish to make a notable change in speed or direction of their car. Non-respect of this regulation will be sufficient to impute fault on the driver in a case where such non-respect leads to an accident.

Equally, a driver is not permitted to stop his vehicle in an abrupt manner, unless it is necessary for safety reasons. Therefore, any driver wishing to slow to an appreciable extent shall first make sure that he can do so without danger or inconvenience to other road users by giving a clear and timely warning.

The driver's attitude on the road while driving therefore has to be one of care and respect for other vehicles and road users and property. What could constitute fault on a driver's part is so broad that the likelihood of him not being at fault in case of an accident is very small. It may not be a major fault but it will have an impact on the incidence of him receiving compensation as a victim of a motor accident for which he is involved.

Other faults which drivers may commit while driving may include; opening their doors in an arbitrary manner such that it causes an injury to another road user, failure to respect rules put in place by the law governing

\footnotetext{
${ }^{35}$ Negligent driving is defined as breaching a certain duty and thereby causing damage. In terms of motor accidents, this means that the driver failed to do or not do, something which he or she would have done and this resulted in an action causing damage.

${ }^{36}$ See Section II (1) Decree No. 79/341 of 3 September 1971 instituting the Highway Code.

${ }^{37}$ See Section II (2) of Decree No. 79/341 of 3 September 1971 instituting the Highway Code.
} 
change of direction, overtaking and their behavior when they are to be over-taken, their obligations towards pedestrians, standing and parking, crossing of bridges, ferries and a host of other instructions and regulations.

As stated above faults that could be committed by the driver can be grouped into a spectrum. However, these faults are not only limited to those which can be committed while driving but also to those that could be imputed on the personality of the driver. These may range from his qualification and the type of driving permit he holds, his health as well as his mind set at the time of entering into the vehicle. It is only logical and of good practice that drivers should have a valid permit and equally drive the category of vehicles which they are permitted to drive. Being of good health will simply require them to be medically fit to drive a vehicle. Little wonder why some people, based on the precarious states of their health and the unsoundness of their mind are restricted from driving motor vehicles. Therefore a driver against whom it is proven that had an unsound mind may be held to be at fault in the case where he is involved in a motor accident. Evidence of an unsound mind maybe adduced whereby showing that the driver was driving under the influence of drugs such as cocaine and other banned substances for drivers while they drive such as alcohol. It is considered that a driver with an unsound mind even with good driving skills cannot reasonably appreciate events on the road and effectively apply such skills which he has obtained from driving license. Therefore in such a case the road is not an ideal place for him to take his chances. The requirement for a valid license is buttressed by decree No 79/341. However processing a drivers' license does not automatically exonerate the driver from any form of fault that could be imputed based on his qualification. This is because holding a valid driving license and driving a vehicle whose category is not covered by that driving license held by the driver could also constitute default on the part of the driver in case of the occurrence of an accident ${ }^{38}$.

\subsection{Proof of Fault on the Part of the Driver}

It should be noted that only the fault committed by the driver which subsequently led to the occurrence of the accident is to be used in determining whether the driver should get compensation or not. There must therefore be a causal link between the driver's fault and the accident. The burden of proof of fault on the part of the driver is however incumbent on the defendant of the claim. Such fault will be appreciated based on the dexterity of the individual defendant. Such a defendant may demonstrate imprudence. Negligence on the part of the driver like proving that the driver was on high speed, the driver demonstrated willful disregard of the traffic signs etc. The defendant can only be exonerated from compensation either totally or partially where he can prove that the fault committed by the driver either directly or indirectly led to the occurrence of the accident. Therefore it is not sufficient to prove fault on the part of the driver but the defendant must equally go ahead to prove that such fault directly or indirectly played a role in the occurrence of the accident.

Faults related to the person of the driver are usually easy to proof. In effect there is nothing easier for police and gendarmerie officials than testing a driver for alcohol, checking validity of licenses or insurance of the vehicle. It is sufficient for these individuals to carry out on the spot test to check if he was driving under the influence of alcohol or if he was in possession of the required administrative documents. In this case, proof of fault is objective and quasi-incontestable.

Proof of fault does not however follow suit when it concerns faults committed while driving. This is why the learnt Professor A. Tunc commented that to better appreciate who is responsible for what in an accident; you must have filmed the accident during its occurrence [6]. Proof of this category of faults cannot be done exclusively in an objective manner. This is because of the reliance on imprecise testimonies, excess of speed which is only presumed. The degree of appreciation may vary from country to country. In advanced countries of the western world, it is much easier than in an "aspiring to become an emerging nation by 2035" country like our own. This is because countries belonging to the former have developed technologies and techniques far beyond our capacity. They even possess wad cameras on major points of the highway which register accidents and make it easier for the police to determine faults long after the accidents have occurred. But in a country like ours it becomes difficult and practically impossible to determine responsibility after a road accident has occurred because of the lack of the appropriate technology, skills and equipment.

\subsection{Effects of the Driver's Fault}

Where the driver's fault has been proven, it produces energetic consequences. These consequences can be better

\footnotetext{
${ }^{38}$ Article $42(1)$ gives an elaborate analysis of the various categories of driver's license and the specific category of vehicles attached to each
} category of license. 
analyzed in terms of sanctions. This is clearly stated in article 227 of the CIMA Code. Punishments for faults committed by the driver also form a part of the Badinter Law ${ }^{39}$.

However, it becomes incumbent on the judge to appreciate the gravity of the fault and to determine whether the driver should be partially or completely excluded from compensation where his fault is proven or award him his full compensation where no fault has been established.

At this point, it becomes necessary to consider the case of accidents between many drivers, where it becomes difficult to apportion responsibility. In this case, responsibility is shared based on the role each the driver played in causing the accident. This was the view taken in judgment No. $971 / \mathrm{cor}^{40}$ of the Bafoussam Court of Appeal. In this case, three vehicles were involved in an accident and subsequently each driver was claiming compensation from the other. The judge shared the compensation to be received as follows: The first driver was responsible for 7/10 of the damages (Chin Boniface). The second driver received for 3/10 (Tcoffo Bertin) while the third driver was simply excluded from benefitting from any compensation (Moghu Boniface).

\section{The Compensation Procedure}

The occurrence of a damage caused by a motor vehicle gives rise to a right to receive compensation on the part of the victim. But however, this is true for all categories of victims except the driver-victim. This is because unlike other categories of victims, the driver's fault is taken into consideration to determine whether he could be compensated or not. Where he is at fault, the gravity of the fault will be appreciated by the judge. After appreciation, the judge will now decide whether he will receive partial compensation or if he will be completely excluded from any form or amount of compensation or if he will receive full compensation. Where no fault is established on the part of the driver or where he is entitled to receive partial compensation, the parties then proceed with the compensation procedure.

Where the driver alone is responsible for the accident for example in a case where he falls in a valley or collides with a tree, the driver can only benefit from compensation if he contracted a specific insurance policy or where there is a clause in the insurance policy which guarantees compensation for him in such situations .In such cases, compensation will be limited to the values stated in the policy and what will constitute prejudice is enumerated in the policy. Here, it is the insurer of the vehicle who has the burden to pay or the Motor Insurance Fund $[7]^{41}$. This fund pays indemnity to victims who sustain bodily injuries as a result of motor accidents, where the person that caused the accident is unknown or the person is known but incapable of compensating the victims. While waiting for the putting in place of such a mechanism in Cameroon, the actions by the driver for the main time could only be directed towards the insurer of the person responsible. It should be noted that compensation is limited only to corporal damages or to corporal and material damages. Damages that affect only property are compensated by agreements between the victim, the insurer and the person responsible. The compensation procedure however begins with the process of amicable compensation ${ }^{42}$ which must mandatorily be initiated by the insurer of the person responsible. The CIMA Code has considerably simplified and accelerated compensation procedure by instituting amicable settlement. In this regard, amicable settlement is obligatory and a prerequisite to all proceedings. The domain of intervention by the judge has been reduced and relegated to the periphery giving priority to the parties concerned.

\subsection{Offer of Compensation 43}

This is the first step towards amicable compensation ${ }^{44}$. It is usually initiated by the insurer of the person responsible. This role was formerly played by the victim. Where he failed to come into an agreement with insurer, he would seize the jurisdiction of the courts and the power of a judge to decide what will be payable as compensa-

\footnotetext{
${ }^{39}$ Article four states that the fault committed by the driver of the vehicle has the effect of limiting or excluding him from any compensation for the damage he has suffered as a result of the accident. As stated above the fault should be that which has a causal link with the accident. ${ }^{40}$ Of 5 August 2003.

${ }^{41}$ This fund was established in Cameroon by Decree No. 67-DF-495 of 17 November, 1967.

${ }^{42}$ Amicable settlements have been made mandatory under the CIMA Code and in Article 225 (2), it is referred to as "Compromise".

${ }^{43}$ Article 231 of the CIMA Code.

${ }^{44}$ The CIMA Code has clearly taken a position in favour of amicable settlement by promulgating precise obligations on the insurer, the victim, the state and by protecting the victim before, during and after the process of amicable settlement. The insurer must be informed about the accident within the period of one month from the date of its occurrence. By virtue of article 230 of the CIMA Code, a copy of any report on bodily injury from a road traffic accident must be submitted to the insurers concerned with the said accident by officers or agents of the judicial police within three months from the date of the occurrence of the accident.
} 
tion for bodily injuries suffered by the victims. The compensation procedure begins with amicable settlement as a means of compensation for bodily injuries. This insurer is obliged by the law to initiate this procedure by making an offer of compensation. The insurer can therefore no longer sit and wait on his comfort seat while the victim initiates the procedures for amicable compensation. He is now expected to put in place the proper mechanism for compensation. The insurer and the victim have often settled claims out of court ${ }^{45}$. Any party who desired out of court compensation would approach the other and make a proposal and the other is free to accept or reject it. It was the victim who usually approached the insurer. This is due to a couple of reasons. Firstly, they experienced difficulty in determining the civil liability of the parties in the realisation of the accident. Secondly, damages sustained were rather very serious and thirdly, the insurance companies were confronted with excessive claims from the victims. Amicable settlement is quite advantageous. This is because sometimes it is faster and less expensive for the parties. However, this period must fully be observed and it is only after this period is over that litigations can be entertained in court. Where a party opens litigation proceedings in court before the lapse of this time period, such will be thrown out by the courts. This was the decision taken by the Limbe Court of First Instance in the case of The People of Cameroon and Tamokwe's Family v. NgaiwiKintashe Fidelis, PekouVingtcent and Satellite Insurance Co. ${ }^{46}$

\subsubsection{The Obligation to Make an Offer of Compensation}

This obligation is to be exercised by the insurer of the person responsible to the insured. This is the provision of article 231 of the CIMA. But one may ask the question, why did the legislator decide to make this procedure obligatory against the insurer? The major reason for the adoption of this provision is because the provisions of the Civil Code did not afford adequate protection to the victims [8]. After reading this article, one could also come to a conclusion that it is incumbent on the insurer to initiate proceedings for amicable settlement so as to prevent the victim from the financial prowess of the insurer and also to ensure that poor victims are able to get compensated without spending excessively. This is because generally the compensation procedure will mean incurring extra cost plus damages suffered on the part of the victim. It is however very logical that the insurer usually rich and powerful bears the cost for such a burden ${ }^{47}$. This is however an innovation on the part of the CIMA Code, departing completely from the Civil $\mathrm{Law}^{48}$.

The entire idea of amicable compensation is linked to the notion of alternative dispute resolution or out of court settlement. This is important because court judgments may sometimes not be satisfactory. The period for settlement of claims could equally be so long and cost expensive to the parties especially to the victims who are many at times poor and can't even afford paying personally for treatment of injuries sustained as a result of the motor accident. Above all, this is an effective means of enforcing peaceful co-existence between the parties even though one has suffered both corporal and material damages caused by the other. Through this process, their differences could be resolved amicably through understanding. Where an amicable compensation process goes through successfully, the parties are likely to be thereafter with everyone fully satisfied. This may not however be the case after a court judgment where the decision is imposed on everyone without their consent and carrying an executor y force. This has the effect of leaving the parties separated with a feeling of mutual disagreement which blocks the possibility of Future Corporation for any other reason no matter how important it may be. On the other part of the victim, he may lose confidence in the insurance industry and this is thus bad for the economy because the insurance industry plays a vital role in bringing about economic growth. Thus amicable compensation is a highly responsive method of achieving a lot both by the insurance company, the state and the victim. Everything is done to ensure that the victim does not lose faith in the insurance industry and that is why where he does not feel satisfied with the insurers' offer during amicable compensation, he has a right to continue proceedings in court.

According to article 231, the insurer has maximum of twelve months ${ }^{49}$ to present an offer of compensation to the driver-victim. One can hardly understand why the legislators of the CIMA Code would give the insurer up to twelve months for him to make an offer to the victim given that the code gives the police officers a maximum of three months ${ }^{50}$ to submit all reports. This gives us a maximum period of 15 months ${ }^{51}$ after the occurrence of the

\footnotetext{
${ }^{45}$ This is referred to in arbitration as Alternative Dispute Resolution (ADR).

${ }^{46}$ Suit No. LM/318 cc/2005, Limbe (Unreported).

${ }^{47}$ This was however not the position under the Common Law as the victim had the responsibility to initiate such procedures.

${ }^{48}$ Under the Civil Law, it was incumbent on the victim to initiate the proceedings for compensation.

${ }^{49}$ From the time they receive a copy report of bodily injuries sustained by the driver-victim.

${ }^{50}$ Article 231 of the Code.

${ }^{51}$ This time period is considerably long for a law which was put in place to facilitate and accelerate the compensation procedure.
} 
accident before the driver-victim could receive a compensation offer from the insurer concerned. This is particularly very long and considering the fact that, one of the reasons of putting in place the code was to accelerate the compensation procedure.

However, the CIMA Code has put measures in place to ensure that this time limit is unequivocally respected. This is by making provisions for sanctions in cases of late offer of compensation. In this light, the Code states that where the offer was made after the time limit stated in article 231, the amount of the compensation shall automatically yield interest. This interest shall be twice the bank discount rate within the limit of the usury rate from the time of the expiry date up to the time the offer becomes final ${ }^{52}$. However and like always, the Code always tries to put the parties on fair grounds and by so doing tries to make sure that the insurer is not unnecessarily punished for what is not his fault. The legislator has therefore envisaged a scenario where the insurer may not necessarily be the cause of the late offer. Of course in a process where the role of the parties is interwoven like a spider web, and what could be referred in labour law as "team work", the inactivity of one person or the slow execution of an activity by one person in such a chain, will automatically have the effect of slowing down the effectiveness of the group especially those reliant on the former's execution of his task so as to accomplish theirs. In this light, the Code states in article 233 that;

“...this penalty shall be reduced or nullified by reasons of circumstance not attributable to the insurer and notably, when it does not have the address of the victim".

The period provided for the offer of compensation may be extended or suspended ${ }^{53}$. These are in cases where the victim dies ${ }^{54}$ or there is disagreement on the expert report or the choice of the medical doctor ${ }^{55}$. In these cases, it may be extended by one month. The period of offer may be suspended in case of delay in the declaration of the accident to the insurer and delay in the communication and submission of supporting documents by the claimants to the insurer. The victim has six weeks ${ }^{56}$ to respond to the correspondence by which the insurer request for information. The period of offer is suspended until the reception of the letter containing the information requested. However in the case where the claimant supplies incomplete information beyond the six weeks provided by the Code and the insurer does not request for full information, within a period of one month from the date of the reception of the letter, the period of the offer starts running again ${ }^{57}$. But where the claimant (victim) supplies incomplete information during the six weeks period, the insurer has just fifteen days to request for full information, failure of which the time limit of offer will not be suspended. It is only normal that the period of offer keeps running in the latter case. The desire of the legislator to accelerate the compensation procedure could better justify this position of the law. The insurer is therefore expected to apply utmost good faith in his dealings with the insured. Therefore where for one reason or the other, the insured fails to supply the insurer with the complete information he required, the insurer noticing this has the good faith obligation to notify the victim about the missing information. This is therefore in a bid to ensure that insurers do not act in malice when they are faced with such a situation knowing that, the period of offer would remain suspended and thus delay the compensation procedure as long as possible. This shows that one of fundamental objective of the CIMA Code is the protection of motor accident victims. It is this basic objective which led the legislator to simplify the role played by the victim or his beneficiaries during the settlement process. The insurer takes all the initiative and the victim simply replies to requests from the insurer. The CIMA Code states all the information and documents to be submitted by the victim ${ }^{58}$ or his legal claimants ${ }^{59}$, in order to guide and clarify the insurer throughout the settlement process. The driver-victim or the beneficiary must submit to the insurer the list of third party contribu-

\footnotetext{
${ }^{52}$ See generally article 233 of the Code.

${ }^{53}$ Article 247.

${ }^{54}$ See article 248.

${ }^{55}$ See article 252 .

${ }^{56}$ See article 249.

${ }^{57}$ Article 251.

${ }^{58} \mathrm{By}$ virtue of article 240, the victim must, at the request of the insurer present the following information: last and first names, date and place of birth, professional activity and address of employer(s), amount of professional income with relevant supporting documents, a description of bodily injuries incurred and a copy of initial medical certificate and other documents of proof in the event of stabilization, a description of damages caused to property, the last, first names and address of the persons for whom they are responsible at the time of the accident, a list of third party payers called out to pay benefits to him and the location to which correspondence must be addressed. The victim must at the request of the insurers produce the following documents; identity card, birth certificate and marriage certificate.

${ }^{59} \mathrm{By}$ virtue of Article 241 of the CIMA Code, the legal claimants must at the request of the insurers provide the following documents: last and first names, date and place of birth of the victim, relationship of the victim, name and address of employer(s), amount of professional income with supporting documents, a description of loss, notably expenses of any of any type which he incurred due to the accident, a list of third parties called on to pay out benefits to him and the location to which correspondence must be addressed.
} 
tion or any collateral payments. The aim of requiring the driver-victim to or his beneficiaries to submit a list of third party contribution or any collateral payments is to ensure that the driver-victim does not get double compensation and by so doing make gains out of an unfortunate situation ${ }^{60}$. The last sentence of article 233 above however enumerates circumstances in which the penalty for late offer of compensation may be nullified or reduced. What could be deduced here is the legislator attempting to create equilibrium between the interest of the victim and that of the insurer. The insurer should reasonably not be held liable to pay penalties for an action not emanating of them an independent by all means of their own volition. The particular scenario cited by the code only goes to buttress this point of view. It talks of the situation where the insurer does not have the address of the victim. This point need not be over emphasized, taking into context the geographical scope of application of the CIMA Code. Most countries applying the CIMA Code have very poor town planning systems where it is very difficult to easily situate the residence of someone. The database systems for situating the residence of individuals are not computerized and sometimes residencies are even changed without giving any notification to the local authorities in charge of keeping such records. In Europe, North America and other industrialized and advanced countries, such a provision would be of very little relevance. But in a context like ours, one cannot deny the importance of such a provision especially to insurers and for the protection of the insurance industry. This problem is further compounded by the victims and their supply of inadequate information to the insurer especially where details about their residence are omitted whether deliberately or unintentionally such that it has the effect of leading to the payment of penalties for late offer by the insurer. Why would the insurer therefore be held liable for a fault or negligence committed by the very victim who he is fighting to compensate? Perhaps, this is the reason why the Code has made provisions for extensions of the period of offer where the insurer has not received complete information from the victim or his claimants within the scope of time provided for by the Code $^{61}$.

\subsubsection{The Scope of Offer}

The CIMA Code has clearly stated the scope of the offer for compensation. This is the content of article 231, which clearly states as follows:

"The offer shall include all items which may be subject to compensation those pertaining to property damages when they have not been the object of prior settlement. It may be of a temporary nature when the insurer has not, within six months following the occurrence of the accident been informed of the stability of the victim's state of health. The final compensation offer must, then, be made within a six months time limit following the date on which the insurer was informed of his stability ${ }^{62, "}$.

A reading of the above provision clearly two things: firstly, provision has been made for the compensation of property damages and secondly the Code has made provisions for periodic payments. In respect to the former, compensation is only possible for driver-victims who do not suffer only property damages. By extension, to be eligible for compensation, the driver-victim must suffer both corporal and material damages. It is therefore the intention of the legislator to limit the scope of offer. This could clearly be interpreted as an act by the legislator aiming to protect the insurer. A hypothetical illustration could be as follows; Samuel suffers bodily injuries as well material damages as a result of a motor accident in which he is a victim. At the same time, Thomas suffers from material damages which have been caused by the same accident. The question that arises here is will the insurer make an offer of compensation to Thomas who suffers only material damages as well as to Samuel who suffers corporal damages as well material damages from the same accident? The answer to this question is clear and without any ambiguity. The offer has to be made to the person who suffers both material and corporal damages simultaneously. However in all these, and as stated above, the driver's fault is taken into consideration to determine his eligibility for compensation. The CIMA Code therefore clearly makes a distinction between bodily and material damages when it comes to the victim non-driver. With respect to material damages, the contributory negligence or fault of a victim who is not the driver will be taken into consideration, to exclude or apportion his right to compensation ${ }^{63}$. This is one area where the CIMA Code puts the driver-victim and non driver victims on one footing. Their faults are taken into account and until it is proven that they played no part in the occur-

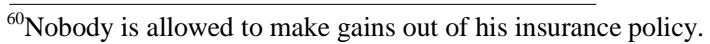

${ }^{61}$ Article 250.

${ }^{62}$ Article 231(2).

${ }^{63}$ Article 228(3) of the CIMA Code.
} 
rence of the accident that caused the material damage, they cannot be compensated for such damages. Therefore, the gravity of the victim's fault will determine whether they will receive full or partial compensation or if they may be completely or partially excluded from any compensation. In respect of the latter, in the case where the injuries have not yet stabilised within six months, as usually will be the case where the injuries are serious, the offer for compensation maybe a provisional one ${ }^{64}$. In this case, a final offer must be made within a maximum period of six months from the date on which the insurer is informed that the victim has made maximum recovery ${ }^{65}$. This provision is of a great importance because the provisional offer would enable the victim to receive medical attention early enough to reduce the level of disability. It is often said "a stitch in time saves nine" and "prevention is better than cure". By aiding the victim to rapid recovery the total amount of compensation may be limited. This method has been seen to be very advantageous to the victims. Advocates of No-fault liability argue that periodic payments that are the payment of losses as they accrue will not only alleviate the financial crisis of early losses but will also encourage the rehabilitation. They also claim that periodic payments will ensure the availability of funds for long term losses. English law gives the judge no power to order payment of damages on regular periodic sums. The law allows once-and-for-all compensation to claimants. If the plaintiff's injury later deteriorated, he cannot turn round and reopen the trial as he is entitled to only one trial in which he is compensated, with an arbitrary sum. Where injuries are not serious, problems hardly arise because there is the possibility of the driver victim returning to work long before the damages are assessed. One could equally acknowledge the existence of a problem linked to periodic payments. The Code has not indicated the situation where an amicable settlement fails and the case goes to court for resolution. What would become the process of periodic payments? It is the opinion of this researcher that periodic payments should be extended right up to the period during litigation, where amicable settlement fails.

In the case of death of the victim, the insurer is obliged according to Article $231(2)^{66}$ to make an offer of compensation to the rightful beneficiaries of the victim ${ }^{67}$. The offer is made to his legal claimant(s) with a maximum period of 8 months following the death of the victim. When the offer is not made within this deadline laid down in article 231, the amount of compensation shall automatically yield interest ${ }^{68}$. This interest shall be twice the bank discount rate, the penalty shall be reduced or nullified by reason of circumstances not attributable to the insurer and notably when it does not have the victim's address ${ }^{69}$.

If there are several insurers, the insurer who has a mandate given by the others in the compensation agreement will make the offer on their behalf $f^{70}$. The offer must indicate all compensable heads of damages including those related to the victims or beneficiary must be clearly stated. The insurer must indicate the name of the agents who is responsible for the handling of the particular file in the company. This is in a bid to give the victim a clear idea of how the files are being managed. The driver-victim or legal claimant reserves the right to repudiate the amicable settlement within 15 days of its signing ${ }^{71}$. This must be done by registered mail. Any clause in the agreement by which relinquishes the claimants' right of repudiation shall be void ${ }^{72}$.

In order to protect the interest of the victim and to ensure the respect of the deadline by the insurer to offer compensate to the claimants, the code has envisaged sanctions in the case of late offer and payment. Within the prescribed time limits, the sum not paid is subject to interest at a discount rate increased by half for the first two months. At the expiration of these two months, the discount rate doubles. However, if the delay is due to circumstances independent of the insurer, for example if he does not have the address of the victim, then the penalty may be reduced or cancelled. Furthermore, in most countries there are inherent communications difficulties promoted by poor roads and contribute to inefficient telecommunication services. These difficulties do prolong the compensation procedure envisage by the CIMA Code and thus defeat one of the objectives which the code sets out to achieve which is the rapid compensation of victims.

\footnotetext{
${ }^{64}$ Article 231 of the CIMA Code.

${ }^{65}$ Article 231(3) of the CIMA Code.

66، In the event of death of the victim, the offer shall be made to their rightful beneficiaries within eight months following the death as laid down in article 265 and 266”.

${ }^{67}$ As stipulated in articles 265 and 266.

${ }^{68}$ Article 233.

${ }^{69}$ See generally articled 233.

${ }^{70}$ Article 231(4).

${ }^{71}$ Article 40.

${ }^{72}$ Article 235.
} 


\subsubsection{Content of the Offer ${ }^{73}$}

This is the import of article 243 of the Code. According to this article, the offer shall specify where applicable, compensation limitations or exclusions by insurers, as well as the reasons thereof. The compensation offer must equally indicate how each loss has been assessed and the amounts which are due the beneficiary. This provision once more demonstrates the spirit of the Code to facilitate the compensation procedure and to ensure transparency and acceleration in the compensation of victims. Through this provision, it becomes easier for the drivervictim to accept or reject the proposal made by the insurer, just by glancing on the offer itself, taking in to consideration the insurer's analyses and the proposed amounts. By this, it facilitates the compensation procedure and ensures transparency in the entire process.

\subsection{The Assessment of Damages}

The CIMA Code does not make provisions for special and general damages like under the Common Law in the case of a motor accident. The Code has rather made provisions for specific heads of damages which may be compensated in the case of an accident caused by a motor vehicle, it trailers or its semi trailers. These losses have been stipulated in article 258 - 266 of the Code. The question which is raised here is how we evaluate bodily injuries or the life of a person financially in the case where the victim dies. The CIMA Code enumerates damages which may give rise to compensation ${ }^{74}$. As earlier stated, the victim or insured cannot be allowed to make gains as it will be a breach of the fundamental purpose of an insurance contract. In this respect, the CIMA Code provides three fundamental tools which enable the parties to compromise reasonably liability scale, a functional scale which indicates disability and a compensation table matched with a conversion table.

The functional scale defines the different functions of the human body and indicates the rate of invalidity. This scale consists also of an illness evaluations section to determine the level of incapacity. The introduction of these tools into the code gives them a sending force causing medical experts, judges and legal practitioners to conform to the provisions in force and maintain consistency in the evaluation of damages.

\subsubsection{Damages Compensable to the Driver as a Direct Victim}

A direct victim is someone who suffers material or corporal damages or psychological damage as a result of the accident. Therefore, as earlier stated, the Code has distinguished two types of compensable damages which are those that are linked to property or material damage ${ }^{75}$ and corporal damage. The following heads of damages are compensable with regards direct victims:

- Expenses incurred as a result of the accident (Article 258) [9]

All expenses incurred as a result of the accidents, like the cost of hospitalisation, medical expenses; pharmaceutical and orthopaedic bills are completely catered for by the insurers. However, the Code thus limits the maximum amount of such bill to twice the tariffs of public hospitals ${ }^{76}$. This subsection was however deliberately coined this way in order to take into account the economic situations of different CIMA member states. Setting particular amounts would have been prejudicial to insurers in some member states; therefore setting ceilings and limits that apply the same to all member states is a better and preferable solution. Cost on the insurers will therefore vary depending on the medical costs of each country and as well as the individual rates and tariffs applicable therein. This provision is or could however be prejudicial to certain categories of victims who require intensive medical care necessitating highly sophisticated medical facilities. This is because most public hospitals in Cameroon are highly under equipped and cannot afford the desired medical care needed by some victims. Therefore these patients only have to turn to private hospitals which are almost always having the better equipments when compared to public hospitals. But with this limit to what the insurer may pay as compensation for such medical expenses, private clinics can therefore not provide this desired medical care for fear of not being able to recover the cost of treatment of victims from the insurers. This may have the effect of causing victims to

\footnotetext{
${ }^{73} \mathrm{C}$ See article 243 of the Code.

${ }^{74}$ Articles 257-265 of the CIMA Code.

${ }^{75}$ Reparation of damage to property or material damage constitutes an innovation brought by the CIMA Code.

${ }^{76}$ Article 258(1) states that "expenses of any kind may either be reimbursed to the victim upon presentation of justifiable documents or be directly payable by the insurer of the vehicle that caused the accident”. This article has been modified by the Council of Ministers on the 24 April, 1999. The new sub article 258(2) states that the cost of medical expenses shall not be more than two times the cost of a public hospital and in the case of medical evacuation, the medical cost should not be more than double the cost of public hospitals in the receiving country.
} 
suffer more damage as a result of the accident due to ineffective treatment as medical complications that could have been properly treated are abandoned to become more complicated and destructive to the health of the victims.

One thing that could equally be observed under this article is that the legislator has included the possibility of a patient being evacuated abroad. This could be considered as an innovation under the Code because this was not the case before this particular article was amended. Allowing a possibility for the evacuation of a victim abroad is a simple acknowledgement by the legislator that our medical facilities and hospitals are not always the best. This however goes in line with one of the Code's main objective which is to afford an appreciable protection of victims. However, one would ask why the legislator would insist that only a medical expert report could justify the evacuation of a patient abroad. This may be in a bid to avoid unnecessary expenditures where the particular situation could be treated within the national territory. But the process of checkups and medical justification may be prejudicial sometimes even to the survival of the victim. This is especially as our medical procedures here are very slow and poor medical facilities will just be heavy burdens which at the end the victim is the one who suffers. The Code however, under this section states that in case of evacuation, the medical fees would not exceed the cost once the highest rates of treatments in the public hospitals of the host country.

It should be noted that English law and the CIMA Code show some disparity in this area under English law, no restriction is placed as to cost of medical expenses. Instead the insurers were expected to provide letters of guarantee to victims to ensure that they receive treatment in the hospitals. But with the limitation of the costs, hospitals decline to give victims appropriate treatment fearing they may not be able to pay for bills which the insurer cannot handle. Furthermore, victims are forced to attend public hospitals which are ill-equipped. This may lead to deteriorating state of victims and increase future compensation in the context of other heads of damages.

- Temporal incapacity [10]

This is the period when the driver-victim of a road traffic accident cannot go about his normal activities. It usually runs from the period when he is hospitalised, that is from the day of the accident to the day his health becomes stable. Temporal incapacity is only compensated if the duration fixed by medical experts exceeds eight days and also entails loss of revenue.

The assessment of loss suffered is based on the net income earned six months prior to the accident with respect to wage earners. For non wage earners, the assessment is based on the tax returns of two financial years prior to the accident. For adults who cannot justify income, the assessment is based on the monthly guaranteed minimum wage of the country where the accident occurred. In Cameroon, this has been fixed at 20.000 FRS CFA. If the victim is carrying on a professional activity, be it salaried or not, article 259 of the CIMA Code states that the monthly compensation to be paid does not exceed three times the Annual Guaranteed Minimum Wage. It is in the opinion of this writer that the compensations granted in this context are ridiculously low.

- Permanent disability

This consists of physiological damage, economic and sentimental (moral) loss. Physiological damage refers to pains as a result of wounds left after treatment in the normal functioning of the victim's body. This is manifested by the inability to use certain organs and parts of the body in the same way as the victim did before the accident. It is only compensated if the victim has sustained a permanent invalidity rate of at least $50 \%$. This rate is fixed by medical experts. Conversion tables are used to determine the sums and allowances to be paid.

Economic loss refers to loss of income by the victim who can no longer exercise his former profession. In this case, the compensation is evaluated for both wage earners and non-wage earners on proof of real and justified loss. In any event, the compensation is limited to seven times the A.G.M.W. of the country.

By virtue of the CIMA Code, a victim of an accident will also be compensated for sentimental loss if the permanent disability level is over $80 \%$. The amount of compensation is fixed out the A.G.M.W. The degree of disability is determined by a medical expert ${ }^{77}$.

- Physical suffering

Physical and aesthetic damages are assessed separately on a gravity scale. It ranges from light to exceptional based on medical examination ${ }^{78}$. They are settled based on the annual guaranteed Minimum Wage rates from $5 \%$ s to $300 \%$. This is shown below by Table 1 .

\footnotetext{
${ }^{77}$ Article 260.

${ }^{78}$ Article 262.
} 
Table 1. Gravity scale and compensation rates ${ }^{79}$.

\begin{tabular}{ccc}
\hline 1 & Very light & $50 \%$ \\
\hline 2 & Light & $10 \%$ \\
3 & Moderate & $20 \%$ \\
4 & Average & $40 \%$ \\
5 & Quite severe & $60 \%$ \\
6 & Severe & $100 \%$ \\
7 & Chronic & $150 \%$ \\
8 & Exceptional & $300 \%$ \\
\hline
\end{tabular}

- Career damage ${ }^{80}$

The sixth category is career damage ${ }^{81}$. Under this category, there are two types of victims. These include;

- Loss of opportunity for a pupil or a student

- Loss of a career sustained by a person already in active life.

In the first case, the compensation granted is limited to twelve months of official scholarship. Unfortunately, the CIMA Code does not state the amount of the scholarship. The law is also silent on the compensation to youths who are not in school. It ignores the fact that some children perform services for their parents. In the second case concerning loss of a career, the amount of compensation may not exceeds six months of income and this is further limited to three times the annual guaranteed Minimum Wage.

\subsubsection{Situation Where the Driver-Victim Dies}

In the event of death of the victim, the legal claimants are entitled to three types of damages: Funeral expenses, economic loss and sentimental loss.

- Funeral expenses ${ }^{82}$

Funeral expenses are reimbursed on presentation of supporting documents within the limits of the annual guaranteed Minimum Wage. By virtue of Decree $N^{\circ} 90-1197$ of 3 August $1990^{83}$ determining the degrees of incapacity and valuation of compensation in accident matters, the amount paid for funeral expenses was previously fixed at 1200000 frsCFA. Under the CIMA Code, the maximum amount payable for funeral expenses is 282.168 francs CFA. This sum is also equivalent to the annual guaranteed Minimum Wage. This amount is payable upon presentation of justifiable documents.

- Economic loss

The CIMA Code indicates the legal claimants who are beneficiaries of this compensation. It restricts compensation to spouses and children under care. Each legal claimant will be awarded an amount calculated from the annual income earned by the deceased. The code institutes a legal formula for the sharing of income of the deceased between spouses and children. The value of the income corresponds to the wage of the legal claimant and according to the conversion table annexed to the code. In the absence of a justified income, the evaluation of economic loss sustained by the legal claimants is done on the basis of the annual guaranteed minimum wage. The duration of capitalisation is at most 21 years for children except on the proof that they are undertaking higher studies. In this case, the limit is extended to 25 years.

- Sentimental loss ${ }^{84}$

This category of loss is awarded to the legal claimants of the victim according to the Annual Guaranteed Minimum Wage as expressed in Table $2^{85}$.

\footnotetext{
${ }^{79}$ Article 262.

${ }^{80}$ Article 263.

${ }^{81}$ Article 263 of the CIMA Code.

${ }^{82}$ Article 264.

${ }^{83}$ Article 11.

${ }^{84}$ Article 266(2).

${ }^{85}$ Article 264.
} 
Table 2. Compensation rates for sentimental $\operatorname{loss}^{86}$.

\begin{tabular}{cc}
\hline Spouses & $15 \%$ \\
Minors & $75 \%$ \\
Adult children & $50 \%$ \\
Parent (first degree) & $50 \%$ \\
Brothers and sisters & $25 \%$ \\
\hline
\end{tabular}

With respect to polygamous marriages, the total amount of compensation granted to the spouses for moral loss may not exceed 300\% of the Annual Guaranteed Minimum Wage.

The CIMA Code however does not provide compensation for all categories of victims. There is no compensation for children under 21 except funeral expenses and sentimental loss which is awarded to parents of the deceased children. No mention is made of extended family relations and victims under the guardianship of the deceased.

\subsubsection{General Damages}

There is no legal basis for the award of general damages under the CIMA Code even though the courts habitually do so. In the case of Ashukem Peter Ngashu V. NdeAzinnwig, Zinkeng Gorethi Tangy for. Satellite insurance Company and Jeumo Samanou Cyprian, Motchecho Simeon and Société Nouvelle d'Assurance Cameroun $(S N A C)^{87}$, the High Court of Buea went ahead and awarded general damages even after counsel for the defence submitted that the was no provision for general damages under the CIMA Code. Also in Mohamadou Babadji and 20 others v. Fokou Augustine ${ }^{88}$, the Court of Appeal affirmed that the was no provision for general damages under the CIMA Code but went forward to award general damages on the pretext that it had inherent jurisdiction.

\subsection{Conclusions}

The compensation of the driver-victim as analyzed above is one of a complex nature. Depending on the circumstances of each motor accident, a driver may either due to the gravity of his fault be partially or totally excluded from compensation. However, we realize that this law has many vacuum and lapses. Many a times, due to the ambiguous nature of some of the provisions, interpretations are left under the whims and caprices of the ordinary law judge. This poses a huge problem because thanks to the diverse nature of appreciating the driver's faults by different judges, drivers get different treatment for similar offences. This is because what may constitute fault to one judge may not necessarily constitute fault to the other or where they are both of acceptance that it's a fault, they may disagree as to the gravity of that fault. This therefore works against the principle of impartiality in the administration of justice and it therefore defeats the very purpose for which the law on compensation was enacted. This researcher is of the opinion that the legislator of the law on compensation should take the pain of succinctly enumerating what will constitute the drivers fault and its gravity on the subsequent amendments of the law on compensation. This will reduce the problem of interpretation and partial administration of justice.

Apart from the vacuum and ambiguities that exist in the law of compensation, the law has generally taken a strict stand towards drivers by basing their compensation on the fault principle or the notion of civil responsibility. This could be explained by the fact that the legislator is trying to deter the drivers from committing faults intentionally. The law aims at increasing the level of diligence and care which drivers must observe while they are entrusted with the lives of humans during driving.

The law has equally put in place compensation limits or what is described as gravity scales. This scale provides a limit for which each type of bodily injuries suffered by the driver can be compensated by the insurer. For example, the law states that the insurer is liable to pay for the medical expenses of the victim, but simultaneously states that this amount shall not be more than three times the amount that could be spent in a public hospital.

\footnotetext{
${ }^{86}$ Article 266.

${ }^{87}(2003)$ Suit No.HCF/34/2000-2001 of $7^{\text {th }}$ March 2003, Buea, (Unreported).

${ }^{88}(2001)$ I.C.C.L.R. 87 at 95.
} 
This therefore limits the victim's access to quality treatment, should in case they prefer to go to a private hospital. This is because the private medical practitioners are scared that they may not get back their complete expenditure from the insurer should they spend much on the victim. It should be noted that most people prefer private hospitals, though they are much more expensive than state run hospitals. This is because of the quality of treatment and care given to victims which is far more effective than what is obtained in most public hospitals. However, one could base his argument on the fact that, the CIMA Code is basically a balance between the interest of two parties who are the insured and the insurer. In as much as the Code strives to protect victims from the economically powerful insurers, it also seeks to protect insurers from excess liabilities as this may force many insurers out of business. The insurance sector is a very important sector in every economy, especially in an "aspiring to become an emerging country by 2035” like our own.

Under the law on compensation, it takes at most 15 months for an insurer to make an offer of compensation. This is considerably a very long period of time especially for a law which one of the intentions of its enactment was to accelerate the compensation procedure. This researcher is of the opinion that this length of time is too long and injurious to the victims as they are left to fend for themselves throughout this period before an offer of compensation is made by the insurer. However, this long period could be explained by the fact that insurers have to get police reports on any bodily injuries resulting from the accident from the officials of the judicial police that drew a report of the accident. This report has to be handed to the insurer within the maximum time limit of three months from the date of the occurrence of the accident and after reception of the report, the insurer has at most twelve months to make an offer of compensation to the victim. This period to make an offer is unreasonably too long. It seems like the legislator has forgotten the plight of the injured victim during this period.

The issue of road traffic accidents in Cameroon and other developing countries today is a major call for concern as they account for more than $85 \%$ of road traffic deaths worldwide. According to SheyMabu, [11] 10\% of untimely deaths today are caused by road traffic accidents. Cameroonian roads have therefore become death traps where the thought of travelling becomes very scary like a nightmare. The is an average daily traffic of 159,114/motor vehicles per year in Cameroon, with a total of 2074 crashes recorded in 2007, 2420 in 2008 and 2091 in 2009 causing 1254, 1473 and 1274 deaths in 2007, 2008 and 2009 respectively and yielding a crude average of 128 fatalities per hundred kilometers driven, 60 times higher than the number obtained in Europe ${ }^{89}$. The average mortality rate per accident varies from $60.5 \%$ to $61.4 \%$ across the years. Pedestrians account for $30.3 \%$ of all deaths and $34.2 \%$ of deaths result from crashes involving motor cycle users. According to the latest WHO data published in 2011, road traffic accident deaths in Cameroon reached 5070 or $2.14 \%$ of total deaths. The age adjusted death rate is $32.59 / 100,000$, ranking Cameroon on the $24^{\text {th }}$ position in the world ${ }^{90}$.

These are highly scary statistics. Over $80 \%$ of these accidents are blamed on driver errors ${ }^{91}$. There is therefore enough justification for the hard-line approach taken against drivers when it comes to compensation. However, driver errors seem not to be the only cause. The bad state of our roads is a major call for concern. Sometimes, the roads are just too narrow for a highway ${ }^{92}$. More should be done to increase the sizes and quality of our roads.

Finally, the hosts of kangaroo driving schools that exist everywhere in the country equally play a great role in facilitating the occurrence of motor accidents around the country. It is common place nowadays to see people possess driving licenses obtained by the aid of driving schools for which they have no knowledge whatsoever about driving. Such persons are largely responsible for many of the motor accidents on our roads today. Others learn driving from car washing points while some learn from mechanic workshops. Until stringent measures are taken by the State to keep such clowns off our roads, valuable lives will always be at the mercy of impostors. It is the opinion of this researcher that strict control measures should be put in place to regulate the activities of driving schools and to curb all corrupt and illegal practices of theirs. By so doing permission to operate driving schools should be given to persons deemed worthy and of good moral and legal standings. There is equally a necessity for strict follow up of driving school activities and impromptu on the spot checks and controls, for the law is only there to compensate the victims instead of tackling the problem from its roots. After all, it is often said "prevention is better than cure", therefore "a stitch in time will surely save nine".

\footnotetext{
${ }^{89}$ See Journal of Epidemiology and Community Health, 2011; 65:A371.

${ }^{90} \mathrm{http}: / / \mathrm{www}$.worldlifeexpectacy,com/cameroon-road-traffic-accidents retrieved on February 17, 2015.

${ }^{91}$ http://allafrica.com/stories/201303190377.html retrieved on February 17, 2015.

${ }^{92}$ This is the case of the Douala-Yaoundé highway.
} 


\section{References}

[1] Tumnde, S.M. (2012) Insurance Law in Cameroon. Presses Universitaires d'Afrique.

[2] Chartier, Y. and Faivre, L. (2000) Droit du Dommage Corporel. Dalloz, Paris.

[3] Tunc, A. (1981) Circulation Routière pour une Loi sur les Accidents de la Circulation. Economica, Paris.

[4] Legeais, R. (1986) l’Indemnisation des Victimes des Accidents. Sirey, Paris.

[5] Hubert, D.K. (2007) Les Conducteurs Victime dans le Droit des Accidents de la Circulation. Mémoire en vue de l’obtention du Diplôme d'Etudes Approfondies, University of Dschang, Dschang.

[6] Tunc, A. (1996) Dixième Anniversaire de la Loi Badinter, Bilan et Perspectives. RC. Ass No4 bis Série.

[7] Liman, B.H. (2002) Etude Contributive sur la mise en place d'un fond de Garantie Automobile dans la zone CIMA. Mémoire DESS: HA YAOUNDE.

[8] Assi, E.H.A., Issa, S.J. and Jacqueline, L.O. (2002) CIMA, Droit des Assurance. Bruylant Bruxelles.

[9] Simon, T.T. (2013) Lecture Notes on Insurance Law. University of Dschang, Dschang.

[10] Tumnde, S.M. (2003) Motor Vehicle Insurance Law in Cameroon. Limbe Design House.

[11] Shey, M. (1983) Deaths on Our Roads: Anyway Out? Cameroon Tribune, No. 472, 6 July 1983. 